\title{
Quality, Distance and Trade: A Strategic Approach*
}

\author{
Emanuele Bacchiega ${ }^{\dagger}{ }^{1}$, Antonio Minniti ${ }^{\ddagger 1}$, and Arsen Palestini ${ }^{\S 2}$ \\ ${ }^{1}$ Dipartimento di Scienze Economiche, Alma Mater Studiorum - Università di Bologna, Italy. \\ ${ }^{2}$ MEMOTEF, Università di Roma "La Sapienza", Italy.
}

April 24, 2012

\begin{abstract}
This paper contributes to the literature on distance and quality by identifying a force contributing to explain the observed increase of the quality of shipped goods with the distance of their destination market. This force originates from the influence of distance on firms' strategic behavior when the quality level of goods is a choice variable for them, and complements the ones already proposed in the literature. Our approach differs from the extant literature because it does not rely on technology or preference/income differentials to identify the determinants and drivers of trade flows. Moreover, it allows to clearly disentangle between the price setting and quality choice of firms. We find that distance has an unambiguously positive effect on the average quality of traded goods. Our results suit the empirical evidence on distance and quality and contribute to the analysis of the determinants of firms' trade performance.
\end{abstract}

Keywords: Product Quality, Distance, Strategic Interaction.

JEL Codes: F10, L13

\section{Introduction}

In the discussion of the determinants of trade flows, the focus of economists has gradually shifted from features such as comparative advantage, increasing returns to scale and consumer preferences to factors operating at the firm level (see Bernard et al. 2007, for a discussion). In particular, firm heterogeneity has been emphasized as a fundamental element to understand the drivers of trade flows. In this respect, the literature recognizes two main dimensions along which firms may be heterogeneous (see, for instance, Hallak and Sivadasan 2009). The first

${ }^{*}$ The authors wish to thank O. Bonroy, S. Brangani, M. Cervellati, D. Dragone, G.I.P. Ottaviano, I. Jäckel, P. Vanin, the audiences at EARIE 2011 Stockholm, BOMOPA meeting, Padua, 2010, ETSG 2010 Lausanne, IO: Theory, Empirics and Experiments Workshop Otranto 2011, and seminar participants in Bologna, Grenoble and Catholic University Milan. The usual disclaimer applies.

${ }^{\dagger}$ Corresponding author, emanuele.bacchiega@unibo.it

¥antonio.minniti@unibo.it

$\S$ palestini@math.unifi.it 
relates to productivity (see, among others, Melitz 2003; Chaney 2008; Melitz and Ottaviano 2008). The other dimension of firm heterogeneity is connected with the quality level of the output (see, e.g., Baldwin and Harrigan 2011; Johnson 2010; Kugler and Verhoogen 2012). ${ }^{1}$ The present paper is concerned with the second type of heterogeneity. In particular, we explore the relationship between the quality level of traded goods and the distance of trading partners. Indeed, recent analyses have unveiled empirical regularities concerning the relationship between the quality of exported goods and both the distance and income of the country of destination. Specifically, they show that unit values (free on board prices) of exported goods increase with the distance of the trading partner, which suggests that firms upgrade the quality level of the goods they export to more distant markets compared to closer ones. ${ }^{2}$ This evidence is robust both at the product and firm levels, see, for example, Baldwin and Harrigan (2011); Bastos and Silva (2010); Helble and Okubo (2008); Manova and Zhang (2012).

In this paper, we identify a firm-based force, originating from strategic behavior, that contributes to explain this stylized fact. For this purpose, we modify the classical model of vertical product differentiation with oligopolistic competition (Gabszewicz and Thisse, 1979; Shaked and Sutton, 1982) to account for distance between trading partners. We use this model to investigate the effect of distance on the quality level of traded goods, when quality is a strategic variable for firms. To make our analysis sharper, we abstract from any supply-side (productivity) differences between trading partners and neutralize any income effect, so as to focus on the pure role of strategic interaction among firms. This approach, therefore, assumes that firms are not negligible with respect to the market. This is consistent with the observation that exporting firms are on average bigger than non-exporters (Bernard et al. 2003, using U.S. data, find that they ship on average 5.6 times more).

Our work directly relates to the flourishing literature analyzing the effects of distance on the quality level of traded goods, as measured by unit values. Many works tackle this issue by using monopolistic competition with homogeneous firms (Helpman and Krugman, 1985), comparative advantage (Eaton and Kortum, 2002) or monopolistic competition with heterogeneous firms (Melitz, 2003). ${ }^{3}$ Recently, useful insights on the behavior of firms exposed to trade competition have been drawn by addressing to the Industrial Organization literature. This strand of literature usually combines consumer and/or firm heterogeneity with partial equilibrium analysis (see, e.g., Verhoogen 2008 and Khandelwal 2010). In particular, Verhoogen (2008) works out a model of North-South trade in which the exporting firms of the poor country ship to the rich country commodities of higher quality relative to those produced for the domestic market, "to appeal to richer northern consumers" (Verhoogen, 2008, p. 489). In general, this literature delivers a mapping between ex-ante characteristics of trading partners - productivity, factor endowments, capability, consumer preferences or income - and the features of trade. More productive firms supply higher-quality products, earn larger profits

\footnotetext{
1 The role of product quality in international trade has been receiving a growing theoretical and empirical attention since the seminal contributions by Linder (1961) and Alchian and Allen (1964).

${ }^{2}$ It is common, in the literature, to measure the quality level of a commodity by its unit value (see e.g. Greenaway et al. 1995 and Wooldridge 2002). Noticeable exceptions are Hallak and Schott (2011) and Khandelwal (2010) which disentangle unit values into quality and quality-related price components.

${ }^{3}$ See Baldwin and Harrigan (2011) for an excellent recapitulation of these approaches and an exposition of their empirical implications.
} 
and are more likely to be exporters, whereas richer countries tend to consume and import commodities of higher quality. Our paper is also related to two other strands of literature. The first investigates trade with quality-differentiated products (see, e.g., Eaton and Kierzkowski 1984; Shaked and Sutton 1984; Flam and Helpman 1987; Motta et al. 1997; Frascatore 2001; Cabrales and Motta 2001; De Fraja and Norman 2004; Schott 2004; Hallak 2006; Choi et al. 2006; Sutton 2007). A second stream of literature analyzes the optimal trade policy under trade with quality-differentiated products, and includes papers such as Herguera et al. (2000, 2002), Zhou et al. (2002), Boccard and Wauthy (2005) and Saggi and Sara (2008). With respect to the extant literature on quality, trade, and distance, the two distinguishing features of our approach are (i) the focus on strategic interaction with quality choice as a strategic instrument and (ii) the elimination of any supply-side differences among trading partners.

In a nutshell, the mechanism we identify is the following. Distance, through transport costs, imposes an anticompetitive burden on exporting firms, which is heavier the farther away the destination market is. Exporting firms strategically react by increasing the quality level of their goods -thus making them more attractive to consumers- so as to (partially) recover the competitive edge eroded by distance. Our modeling choice proves to be useful in two respects. First, it identifies a new force shaping trade flows, which is based on the effect exerted by distance on firms' strategic behavior both in price and non-price competition. Second, it allows us to clearly distinguish between the price-setting and the quality choice (product design) activities, so that empirical implications for prices and qualities are drawn separately. As a last remark, we would like to stress that we are fully convinced that supplyand demand-side drivers play a crucial role in shaping trade flows. Nonetheless, we believe that our work sheds light on a novel, complementary mechanism that has been neglected thus far.

Our modeling strategy is as follows. We consider a model of one-way trade with two firms producing variants of a vertically differentiated commodity at zero costs. One firm is located "away" from consumers so that a transport cost has to be paid to consume the good sold by that firm. We set up and solve a two-stage game in which firms first simultaneously and at no cost select the quality level of the good they produce and then simultaneously set prices. We consider the location where the consumers reside as the "destination market", and focus on the prices set as well as on the quality levels of the goods available there. We show that trade costs and strategic behavior determine the role of "high-" versus "low-quality" producer for domestic and foreign firms, and that they influence the average quality level of goods in the "destination" country for given "roles" assigned to firms. In particular, the main outcomes of our model are the following. First, we identify the conditions under which pure-strategy Nash equilibria with trade exist. Second, we show that distance always increases the average quality level of the traded good.

From an empirical standpoint, our results are in accordance both with the acquired evidence on the positive effect of distance on the quality level of traded goods, and, also, with a higher likelihood of "zeros" in trade patterns as distance (measured by trade costs) increases. Moreover, in the section devoted to the discussion of the results, we argue that if we extend our model to account for a positive relationship between the income of the destination market's consumers and the distance of this market from the shipping country, our model may also 
reproduce the empirical evidence asserting that f.o.b. prices increase with distance.

The paper is organized as follows. Section 2 presents the model and Section 3 solves it. Section 4 discusses our results with reference both to the empirical and theoretical literature. Section 5 proposes some extensions. Finally, Section 6 provides a short conclusion. All of the proofs are relegated to the Appendix.

\section{The Model}

Preliminaries We develop a model of one-way trade with two countries: one is foreign $(F)$ and one is domestic $(D)$. Two firms, one located in each country, produce a vertically differentiated good to sell in the domestic country. To import the foreign good, consumers must pay a transport cost. We investigate the subgame-perfect Nash equilibria in a game where firms simultaneously select the quality level of their goods and subsequently set prices.

Consumers The domestic country is inhabited by a continuum of consumers that are heterogeneous in their willingness to pay for quality. Consumers are uniformly distributed with unit density over the interval $[0,1]$ according to their appreciation for quality, $\theta .{ }^{4}$ Consumers purchase either one or zero units of the good. The utility derived by consumer $\theta$ when purchasing one unit of variant $j$ is $U(\theta)=\theta u_{j}$, with $\left.\left.u_{j} \in\right] 0, \bar{u}\right]$ being the (commonly perceived) quality level of variant $j$. Similarly, let $\rho_{j}$ denote the total price paid by consumers to buy one unit of good $j$. We define $\rho_{j}$ as $p_{j}+t$ with $t \geq 0$ representing the unit transport cost paid by consumers, clearly $t=0$ if the purchased variant is produced locally, otherwise $t>0 .{ }^{5} \mathrm{It}$ is reasonable to assume that transport costs increase with the distance of the trading partner. Thus, here, we will refer to $t$ simply as the "distance" from the foreign firm/country to the destination market. Assume that the utility of no consumption is zero. Following Mussa and Rosen (1978) the surplus of consumer $\theta$ is

$$
U(\theta)= \begin{cases}\theta u_{j}-\rho_{j} & \text { when buying one unit of good } j \\ 0 & \text { when abstaining from consumption. }\end{cases}
$$

Demands are obtained through the standard marginal consumer approach. Consumers choose the version of the good providing them with the largest surplus as long as this is positive, else they do not buy. Let $h$ identify the firm selling the high-quality variant, and, similarly, let $l$ label the firm supplying the low-quality one. ${ }^{6}$ Standard computations return the value of $\theta$ identifying the consumer indifferent between purchasing one unit of the high- and low-quality good and that indifferent between purchasing one unit of the low-quality good and abstaining

\footnotetext{
${ }^{4}$ The parameter $\theta$ is equivalently interpreted as an income index, with higher $\theta$ associated with higher income (see Tirole 1988, page 97).

${ }^{5}$ With this specification the burden of transport costs is on consumers, such that the present is a shopping model. Our results, however, do not change if firms pay per unit transport costs to deliver the good to customers (shipping model). Calculations are available upon request.

${ }^{6}$ By anticipating an equilibrium argument, we assume that qualities are different at an equilibrium with two active firms to avoid price competition with a homogeneous good. See Section 3 and Appendices A-D for a detailed proof.
} 
from consumption. Their expressions are reported in the following.

$$
\theta_{1}=\frac{\rho_{h}-\rho_{l}}{u_{h}-u_{l}} ; \quad \theta_{0}=\frac{\rho_{l}}{u_{l}}
$$

Once the marginal consumers expressions are obtained, the demand system under duopoly is easily derived.

$$
\mathcal{D}_{h}=\left(1-\theta_{1}\right) ; \quad \mathcal{D}_{l}=\left(\theta_{1}-\theta_{0}\right) .
$$

Notice that $\theta_{1}$ and $\theta_{0}$ define the demands' bounds only if they lie within the interval $[0,1]$ and $\theta_{1}>\theta_{0}$. Yet, they may not do for some combinations of prices, qualities and transport costs. In this case, the demand for the imported good vanishes. ${ }^{7}$ Imagine, for example, high levels of $t$ (when transport costs are prohibitively high the foreign good is not traded), or a domestic low-quality good with a quality level "close enough" to the imported high-quality one (all consumers prefer to patronize a -slightly- lower quality domestic producer but save on transport costs). In this case, the demand the domestic firm faces needs to be re-defined accordingly. Furthermore, notice that $\theta_{1}$ is not defined for $u_{h}=u_{l}$. Because in our model both prices and qualities are endogenously determined, this behavior of demand has to be carefully examined when characterizing the possible Nash equilibria of the game. We refer the reader to the Sections devoted to the equilibrium analysis for an accurate discussion on this point.

Firms Because the aim of our paper is to delve into the effects of distance of strategic behavior in determining the direction and characteristics of trade flows, we abstract from any supply-side issue by (a) normalizing firms' production costs to zero and (b) assuming that product design in terms of vertical differentiation is costless as in Choi and Shin (1992). This choice allows us to eliminate from quality setting any effects that are not linked to trade costs to the destination market, and thus to focus on the pure effect of distance on the quality of the shipped good. Firm's profits are, thus

$$
\pi_{j}^{i}=\mathcal{D}_{j}^{i} p_{j}^{i}
$$

where $j \in\{h, l\}$ is the quality level of firm $i=D, F$.

Timing The game we analyze has two stages. In the first stage firms simultaneously select the quality levels of their variants, in the second stage they simultaneously set prices.

Our model then takes the form of a game $\Gamma$ where the players are the two firms $i=D, F$, their strategies are price-quality vectors $\left(p_{i}, u_{i}\right)$ and their payoffs are their profits $\pi_{i}(\cdot)$.

\section{Equilibrium}

The game is solved by backward induction, addressing the price stage first.

\footnotetext{
${ }^{7}$ The fact that some demands may be driven down to zero following parameter changes is not new in the literature on vertical differentiation, both with and without trade, see for example Wauthy (1996) and Frascatore (2001).
} 


\section{$3.1 \quad$ Price stage}

In this section we fully develop the pricing stage of the standard duopoly case only, namely when both expressions in (1) lie within the [0,1] interval. We will cope with the situations when they do not in the Section devoted to Equilibrium Analysis. The solution to this case involves standard calculations in the class of models of vertical product differentiation (see e.g. Gabszewicz and Thisse, 1979), thus it will be quickly dealt with. The pricing decisions of firms depend upon their roles as high- or low- quality suppliers, which, in turn, are determined in the first stage. Thus, we consider the two cases that correspond to the two different branches of game $\Gamma$, in the first (i), the high-quality producer is the domestic firm, in the second (ii), the high-quality producer is the foreign firm.

\section{(i) Domestic high-quality producer}

In this case the $D$-firm has selected the high-quality version of the good at the first stage. Therefore profits accruing to firms are:

$$
\pi_{h}^{D}=\mathcal{D}_{h}^{D} p_{h}^{D}, \quad \pi_{l}^{F}=\mathcal{D}_{l}^{F} p_{l}^{F}
$$

Simultaneous maximization of (4) w.r.t. $p_{h}^{D}$ and $p_{l}^{F}$ respectively yield the following expressions for the optimal first-stage prices. ${ }^{8}$

$$
\hat{p}_{h}^{D}\left(u_{h}^{D}, u_{l}^{F}\right)=\frac{u_{h}^{D}\left[2\left(u_{h}^{D}-u_{l}^{F}\right)+t\right]}{4 u_{h}^{D}-u_{l}^{F}}, \quad \hat{p}_{l}^{F}\left(u_{h}^{D}, u_{l}^{F}\right)=\frac{u_{l}^{F}\left(u_{h}^{D}-u_{l}^{F}\right)-t\left(2 u_{h}^{D}-u_{l}^{F}\right)}{4 u_{h}^{D}-u_{l}^{F}} .
$$

By plugging (5) back into (4) we obtain firms' profits in the second stage:

$$
\hat{\pi}_{h}^{D}\left(u_{h}^{D}, u_{l}^{F}\right)=\frac{u_{h}^{D^{2}}\left[2\left(u_{h}^{D}-u_{l}^{F}\right)+t\right]^{2}}{\left(4 u_{h}^{D}-u_{l}^{F}\right)^{2}\left(u_{h}^{D}-u_{l}^{F}\right)}, \quad \hat{\pi}_{l}^{F}\left(u_{h}^{D}, u_{l}^{F}\right)=\frac{u_{h}^{D}\left[\left(u_{h}^{D}-u_{l}^{F}\right) u_{l}^{F}-t\left(2 u_{h}^{D}-u_{l}^{F}\right)\right]^{2}}{u_{l}^{F}\left(u_{h}^{D}-u_{l}^{F}\right)\left(4 u_{h}^{D}-u_{l}^{F}\right)^{2}} .
$$

As noted above, the duopoly demand system $\mathcal{D}_{h}^{D}, \mathcal{D}_{l}^{F}$ involves non-negative prices and quantities for firm $F$ if and only if the difference between firms' quality levels is large enough. The precise condition is reported in the following.

Remark 1. The foreign firm's price and demand are non-negative under duopoly pricing if and only if $u_{h}^{D} \geq \frac{u_{l}^{F}\left(u_{l}^{F}-t\right)}{u_{l}^{F}-2 t}>u_{l}^{F}$.

If qualities are too similar, the low-quality firm (which is disadvantaged because of transport costs) cannot enjoy a positive market share under duopolistic competition. In other terms, if $u_{h}^{D}<\frac{u_{l}^{F}\left(u_{l}^{F}-t\right)}{u_{l}^{F}-2 t}$ entry in the market is "blockaded". We will expand on this point in Section 4.

${ }^{8}$ Easy calculations show that second order conditions are met as long as $u_{h}^{D}>u_{l}^{F}$, which is true by assumption in case $(i)$. 


\section{(ii) Foreign high-quality producer}

This case mirrors the previous, in that the foreign firm is now offering the high-quality variant of the good. Accordingly, firms' profits now are

$$
\pi_{h}^{F}=\mathcal{D}_{h}^{F} p_{h}^{F}, \quad \pi_{l}^{D}=\mathcal{D}_{l}^{D} p_{l}^{D}
$$

As in the previous case, simultaneous maximization of profits in (7) gives the optimal prices in this case, which are reported hereafter. ${ }^{9}$

$$
\hat{p}_{h}^{F}\left(u_{h}^{F}, u_{l}^{D}\right)=\frac{2 u_{h}^{F}\left(u_{h}^{F}-u_{l}^{D}\right)-t\left(2 u_{h}^{F}-u_{l}^{D}\right)}{4 u_{h}^{F}-u_{l}^{D}}, \quad \hat{p}_{l}^{D}\left(u_{h}^{F}, u_{l}^{D}\right)=\frac{\left(u_{h}^{F}-u_{l}^{D}+t\right) u_{l}^{D}}{4 u_{h}^{F}-u_{l}^{D}} .
$$

Substitution of (8) back into (7) yields the following expressions for firms' profits.

$$
\pi_{h}^{F}\left(u_{h}^{F}, u_{l}^{D}\right)=\frac{\left[2 u_{h}^{F}\left(u_{h}^{F}-u_{l}^{D}\right)-t\left(2 u_{h}^{F}-u_{l}^{D}\right)\right]^{2}}{\left(u_{h}^{F}-u_{l}^{D}\right)\left(4 u_{h}^{F}-u_{l}^{D}\right)^{2}}, \quad \pi_{l}^{D}\left(u_{h}^{F}, u_{l}^{D}\right)=\frac{u_{h}^{F} u_{l}^{D}\left(u_{h}^{F}-u_{l}^{D}+t\right)}{\left(u_{h}^{F}-u_{l}^{D}\right)\left(4 u_{h}^{F}-u_{l}^{D}\right)^{2}} .
$$

Inspection of (8) reveals that the price of the domestic low-quality producer is always positive, whereas the foreign high-quality producer's optimal price (and consequently demand) is positive if and only if $u_{h}^{F}$ is large enough. More precisely:

Remark 2. The foreign firm's price and demand are non-negative under duopoly pricing if and only if $u_{h}^{F} \geq \frac{1}{2}\left(t+u_{l}^{D}+\sqrt{t^{2}+\left(u_{l}^{D}\right)^{2}}\right)>u_{l}^{D}$.

Similarly to case $(i)$, if qualities are too similar, a profit-dissipating price competition prevails, and the disadvantaged firm is the foreign one, which in this case produces the highquality good. Again, we refer to Section 4 for a discussion on this point.

In the ensuing analysis, we will focus on the situation where both firms enjoy strictly positive market shares, so as to rule out duopoly equilibria where one firm has a zero market share even if the price set is nil. With a slight abuse of terminology, we will refer to these "subgame-perfect Nash equilibria with two active firms" simply as "subgame-perfect Nash equilibria".

\subsection{Quality choice}

Let us move now to the core of our paper, namely, quality choice. ${ }^{10}$ We will tackle separately cases $(i)$ and $(i i)$, proving the possible existence of subgame-perfect Nash equilibria in the two cases (Propositions 1 and 3) and performing comparative statics analysis on the equilibrium quality levels (Propositions 2 and 4). We will thus report our main economic results in Theorems 1 and 2 and Corollary 1 . We start with case $(i)$. In the ensuing analysis, for the sake of readability, we will omit the first-stage optimal prices when describing firms' strategies,

\footnotetext{
${ }^{9}$ Again second order conditions are satisfied if $u_{h}^{F}>u_{l}^{D}$.

10 One natural reference for this analysis is the article by Choi and Shin (1992). Their main result is that with costless quality choice and firms located in the same market (no transport costs), the firm producing high quality selects the upper bound in the quality space, $\bar{u}$ in our notation, while its low-quality rival chooses a quality that is $\frac{4}{7} \bar{u}$. Choi and Shin (1992) develop a sequential-move game, while ours is simultaneous-move. By setting $t=0$, our model boils down to the simultaneous-move version of Choi and Shin (1992).
} 
to focus on quality levels instead. ${ }^{11}$ We provide the economic intuition of our results at the end of this section, and we refer to Section 4 for a more articulated discussion on them.

\section{(i) Domestic high-quality producer}

The main result in this case is the following.

Proposition 1. In game $\Gamma$, there exists a unique cutoff value for $t, \bar{t} \in] 0, u_{l}^{F}[$ such that for all $t \in[0, \bar{t}[$ there is one and only one SPNE where the high-quality producer is domestic and the low-quality one is foreign. At this equilibrium, $u_{h}^{D *}=\bar{u}$ and $\left.u_{l}^{F *}\left(u_{h}^{D *}\right)=\underline{u}^{F} \in\right] 0, \bar{u}[$.

Proof. See Appendix A.

We can proceed further by delving into the behavior of the equilibrium strategy $\underline{u}^{F}$ as a function of $t$. Our findings are reported in what follows.

Proposition 2. For every $t<\frac{\underline{u}^{F}}{2}$,

(i) $\left.\underline{u}^{F} \in\right] \frac{4}{7} \bar{u}, \frac{29}{49} \bar{u}[$

(ii) $\frac{\partial \underline{u}^{F}}{\partial t}>0$ in the whole interval $] \frac{4}{7} \bar{u}, \frac{29}{49} \bar{u}[$.

Proof. See Appendix B.

\section{(ii) Foreign high-quality producer}

In case $(i i)$, the main result is summarized in the following.

Proposition 3. In game $\Gamma$, (a) when $t<\tilde{t} \approx \frac{3 \bar{u}}{126}$ and $\bar{u}>\frac{1}{2}\left(t+u_{l}^{D}+\sqrt{t^{2}+\left(u_{l}^{D}\right)^{2}}\right) \equiv \hat{u}$, there exists one and only one SPNE where the high-quality producer is foreign, and the lowquality one is local, in this case, $u_{h}^{F *}=\bar{u}$ and $\left.u_{l}^{D *} \equiv \underline{u}^{D} \in\right] 0, \bar{u}[$; (b) when $t \geq \tilde{t}$, there exists no SPNE with a domestic low-quality producer and a foreign high-quality producer.

Proof. See Appendix C.

As in case (i) we analyze the characteristics of the optimal quality level for the domestic firm $\underline{u}^{D}$. The next Proposition summarizes our results.

Proposition 4. For every $t \in[0, \tilde{t}]$

(i) $\underline{u}^{D} \in\left[\frac{4}{7} \bar{u}, \frac{4}{5} \bar{u}\right]$;

(ii) $\frac{\partial \underline{u}^{D}}{\partial t}>0$.

Proof. See Appendix D.

Propositions 1 and 3 characterize the subgame-perfect Nash equilibria of the two branches of game $\Gamma$. They define parameter regions in the $(t, \bar{u})$ space where the game $\Gamma$ has pure strategy SPNE with both firms selling positive quantities at positive prices.

To finalize equilibrium analysis, however, we need to analyze the relative size of $\tilde{t}$ and $\bar{t}$. The next Lemma tackles this point.

\footnotetext{
${ }^{11}$ According to our choice, firm $i$ 's strategy $\left(\hat{p}_{j}^{i}, u_{j}^{i}\right)$ will be reported as $\left(u_{j}^{i}\right)$.
} 
Lemma 1. At every equilibrium of game $\Gamma, \tilde{t}<\bar{t}$.

Proof. By direct comparison it is easy to obtain that $\tilde{t}<\bar{t}$ as long as $\frac{27}{25} u_{l}^{F}<\bar{u}<\frac{164}{25} u_{l}^{F}$. This condition is satisfied at every equilibrium of the game because from Propositions 2 and 4 we know that $\underline{u}^{F} \in\left[\frac{4}{7} \bar{u}, \frac{29}{49} \bar{u}\left[\right.\right.$ and $\underline{u}^{D} \in\left[\frac{4}{7} \bar{u}, \frac{4}{5} \bar{u}\right]$.

We then complete the equilibrium analysis of this game by putting our results together in what follows.

Theorem 1 (Equilibrium existence). Let $\bar{u}>\hat{u}$ and $t<\bar{t}$.

(i) If $0 \leq t<\tilde{t}$ then game $\Gamma$ has two subgame-perfect Nash equilibria. At the first one the high-quality (low-quality) producer is the domestic (foreign) firm, and at the second one, the high-quality (low-quality) producer is the foreign (domestic) firm.

(ii) If $\tilde{t} \leq t<\bar{t}$ then game $\Gamma$ has one and only one subgame-perfect Nash equilibrium, at which the high-quality producer is the domestic firm, and the low-quality producer is the foreign one.

Part (i) of Theorem 1 states that when distance is "small", there are two equilibria: at the first one, the domestic firm produces high quality whereas the foreign firm produces low quality, and at the second one, the opposite happens. The result that all quality configurations may arise at equilibrium is in accordance with intuition: when distance is small firms compete in "almost" the same country, thus there is no reason for one firm to be more likely the high(or low-) quality producer. ${ }^{12}$ By contrast, when distance is "large" (ii), our analysis predicts that one configuration only arises at equilibrium. Specifically, in the unique equilibrium of the game, the high-quality version of the good is locally produced, while the low-quality one is imported. Transport costs induced by distance impose a lower bound above marginal cost (zero in our case) to the price paid by consumers for the imported good, the domestic producer can exploit this asymmetry and "blockade high-quality entry" on the market by credibly committing to begin a price war with a (almost) homogeneous good. In this case, a foreign firm (producing high quality in the parameter region $0 \leq t<\tilde{t}$ ), anticipating the aggressive behavior by the local firm in the second stage of the game, switches position in the quality ladder and produces the low-quality good. ${ }^{13}$ Thus, distance acts as a credible aggressive-behavior commitment device for the domestic producer.

Next, we enlighten the effect of distance on the quality level of the low-quality variant (see Propositions 2 and 4). The following theorem summarizes our result.

Theorem 2 (Comparative statics). Let $\bar{u}>\hat{u}$ and $t<\bar{t}$. The quality level of the low-quality good is always increasing with distance.

Theorem 2 delivers a clear-cut result. Distance increases the quality level of the low-quality good, and the increase in quality is larger the higher the distance, as long as it is small enough $(t<\bar{t})$ to make trade itself viable.

\footnotetext{
${ }^{12}$ Theorem 1 raises the issue of equilibrium multiplicity, on which we come back in Section 4 when we discuss the relationship between quality and distance.

${ }^{13}$ Contrarily, quality switching does not occur when a foreign firm producing low quality keeps producing the same good as distance increases.
} 
Although the result is the same whether the low-quality producer is domestic or foreign, the economic intuition underlying the two cases is different. Consider first the case of a foreign low-quality producer. Trade costs harm the low-quality foreign firm because they increase the total price paid by consumers for the variant. Then the $F$-firm reaction is twofold. On the one hand, it reduces the optimal price it charges on consumers, so as to dampen the effect of distance on consumers' choice (it is easily ascertained that $\left.\frac{\partial \hat{p}_{l}^{F}(\cdot)}{\partial t}<0\right)$. On the other hand, the $F$-firm attempts to recover the competitive edge eroded by (increased) distance by increasing the utility consumers derive from low-quality consumption through an increase in quality. On top of this, notice that the quality increase makes the domestic and foreign products more similar, intensifying further price competition. Consider now the case where the low-quality producer is domestic. An increase in the transport costs causes an increase in the total price consumers have to pay for the high-quality variant, making it less attractive and dampening price competition. Consequently, the domestic low-quality producer can increase the quality level of its good (and extract more surplus from consumers), and still avoid engagement in a fiercer price war due to more homogeneous goods.

We may combine the results of Theorems 1 and 2 in the following.

Corollary 1 (Quality and distance). The expected quality level of the traded good always increases with distance.

The term "expected" can obviously be dropped for $t>\bar{t}$, while it comes from equilibrium multiplicity when $t \in[0, \bar{t}]$, because each firm has a positive probability to be the quality leader.

\section{Discussion}

In this section we discuss our results with reference to the existing empirical literature to put our analysis into perspective.

Quality and distance. The main message conveyed by our paper (Corollary 1) is that distance increases the average quality level of goods available for consumption in the country of destination. Corollary 1 is in direct reference to the literature highlighting the increase of the quality level of traded goods, the greater the distance of their destination market (Baldwin and Harrigan, 2011; Bastos and Silva, 2010; Johnson, 2010; Helble and Okubo, 2008; Manova and Zhang, 2012). When distance is high enough -case (ii) of Theorem 1- the interpretation is straightforward because the quality level of the imported (low-quality) good increases with distance. When distance is "small" -case (i) of Theorem 1- the interpretation refers to the "expected quality level of import". Indeed, an increase in the distance results in an increase of the quality level of the imported good only when the low-quality producer is foreign, while it has no effect on the import quality level when the low-quality firm is local. ${ }^{14}$ As explained above, however, equilibrium multiplicity makes both configurations ex ante possible. Thus, we conclude that distance causes the expected quality level of import to increase also when trade

\footnotetext{
${ }^{14}$ Recall that the high-quality firm always selects the highest feasible quality level because of costless product design.
} 
partners are "close". ${ }^{15}$ Finally, it is worth noticing that part (ii) of Theorem 1 points out that for a "large distance" the imported good is of low-quality. This should not be considered in contrast with empirical evidence for the following reason. This evidence highlights that the quality level of goods increases with the distance of the shipping destination, but does not claim that exporters become the quality leaders (i.e. the producers of the top-quality available variant) in their destination markets. ${ }^{16}$

Corollary 1 may also be interpreted with reference to the "Alchian-Allen Conjecture" (AAC), which predicts that per unit trade costs increase the consumption share of highquality goods relative to that of low-quality ones in the country of destination with respect to the country of origin (Alchian and Allen, 1964, p. 64). Per unit trade costs, indeed, increase the relative price of the low-quality goods at destination. ${ }^{17}$ The AAC compares consumption shares, thus its mechanism cannot be directly compared to ours. This notwithstanding, the present analysis, suggests that per unit trade costs should also cause an increase in the average quality of consumption because the average quality of the goods itself increases due to trade, not only because the relative consumption of goods of given quality is modified. In particular, the quality level of the imported low-quality goods is higher, the farther away the trading partners are; and the farther the high-quality foreign producer is, the higher the quality of the domestic production.

F.o.b. prices and distance. Product quality is unobservable in general. Empirical research uses average unit value (f.o.b. prices) to make inference on quality, and concludes that quality increases with distance because f.o.b. prices increase with distance. In the version of the model we have presented above, by contrast, f.o.b. prices decrease with distance. This is due to two different effects. On the one hand, it is easy to ascertain from (5) and (8) that, ceteris paribus, the price of any imported good is always decreasing in $t$ : the longer the distance to the trading partner, the higher the "discount" on the f.o.b. price that the exporting firm should set to compensate for the distortion due to transport costs (see, e.g., Melitz and Ottaviano 2008; Kneller and Yu 2008). On the other hand, an increase in $t$ triggers an increase in the quality level of the low-quality good (Theorem 2). This makes variants more homogeneous and thus intensifies the price war, with a decrease, in particular, in the price of the imported good. Both these effects entail a decrease in f.o.b. prices. Yet, our model may accommodate the behavior for unit values that is empirically accepted once the income

\footnotetext{
${ }^{15}$ In models of vertical product differentiation, equilibrium multiplicity at the quality-choice stage is usually dealt with the "risk dominance" criterion (Harsanyi and Selten, 1988). In our model, the complexity of equilibrium values does not allow for a direct application of this criterion. Yet, numerical simulations show that in the parameter constellation defined by Theorem 1, the risk-dominant equilibrium is that with the domestic high-quality producer and the foreign low-quality one. Another possible way out of equilibrium multiplicity is to assume that firms choose qualities sequentially, and then set prices simultaneously. In this case, the quality leader would choose the highquality variant, and the follower would be forced to fill the low-quality product niche. Thus, the equilibrium outcome would depend on how the leader and follower roles are assigned to the firms. However, unless there were a strong argument to assign these roles, both cases would be possible, therefore the actual outcome of the interaction for $t \in[0, \tilde{t}[$ would still be undetermined.

${ }^{16} \mathrm{An}$ example could make this point clearer. Our model predicts that an Italian Merlot wine producer ships to France a higher-quality wine than it does to Central Italy. However, this wine needs not to be the top-quality Merlot-varietal wine in France, as it may be outperformed by some Bordeaux producer. For empirical analyses on the quality of traded wine see, e.g. Crozet et al. (2009); Altomonte et al. (2010).

${ }^{17}$ For a recent treatment of the AAC see Hummels and Skiba (2004).
} 
of consumers is explicitly taken into account. In fact, our choice to set equal to 1 the upper bound of the support of the willingness to pay for quality $\theta$ amounts to normalizing the income of the richest consumer as well, because a consumer's higher willingness to pay for quality is commonly assumed to reflect a higher income of that consumer. A side effect of this normalization is that income disappears in all the equations of the model. If the upper bound of the income distribution were not normalized but set equal to, say, $\bar{\theta}$, then equilibrium prices (and profits) would positively depend on this parameter. ${ }^{18}$ In our case, letting $\theta \sim U[0, \bar{\theta}]$ would yield the following prices in the second stage:

$$
\begin{aligned}
\hat{p}_{h}^{D} & =\frac{u_{h}^{D}\left[2 \bar{\theta}\left(u_{h}^{D}-u_{l}^{F}\right)+t\right]}{4 u_{h}^{D}-u_{l}^{F}} \\
\hat{p}_{l}^{F} & =\frac{\bar{\theta} u_{l}^{F}\left(u_{h}^{D}-u_{l}^{F}\right)-t\left(2 u_{h}^{D}-u_{l}^{F}\right)}{4 u_{d}^{D}-u_{l}^{F}}
\end{aligned}
$$

in case (i) and similar expressions in case (ii). It is straightforward to observe from these expressions that, all else equal, prices increase with $\bar{\theta}$ (a higher income results in a higher willingness to pay for quality and thus firms may charge higher prices). Now, recall that Baldwin and Harrigan (2011) show that the likelihood of "zeros" is negatively related to the country of destination's GDP and positively related to distance. Stated differently, the higher the trading partner's income, the more likely trade is non-zero, and the farther away the partner is, the less likely trade is. Thus, the more distant a country, the more likely this country should be of "high" income if trade flows are non-zero. ${ }^{19}$ This suggests the existence of a positive correlation between distance and income of the trading partner when observing a non-zero trade flow. In our model with non-normalized maximum income, this assumption results in a positive relationship between $\bar{\theta}$ and $t$, namely, $\bar{\theta}(t)$ such that $\bar{\theta}^{\prime}(t)>0$. On the basis of our previous observations, this introduces a force pushing up prices, the farther away the trading partner. The extended model explicitly incorporating income is analytically solvable, but its outcome is not very informative because of the complexity of the equilibrium values. Yet, some useful insights can be drawn by making use of numerical examples. This exercise confirms the trade-off we have outlined above, which is depicted in Figure 1.

The "flat" surface represents $p_{l}^{F}\left(\bar{u}, \underline{u}^{F}(\bar{\theta}, t)\right)$ - the price of the exported good in case (i) - for $\bar{u}=3$. The f.o.b. price decreases along the distance axis $t$, whereas it increases with income of the consumers in the destination market, $\bar{\theta}$. The functions on the surface represent two possible relationships between $\bar{\theta}$ and $t$. The function $\bar{\theta}^{1}(t)$ (dashed curve) is characterized by a "slow" increase of income with distance, while in $\bar{\theta}^{2}(t)$ (solid curve) income steeply increases with it. If the relationship between the distance to the export market and the income of the trading partner is as in $\bar{\theta}^{1}(t)$, then the f.o.b. price decreases with distance, while if it is as in $\bar{\theta}^{2}(t)$, the f.o.b. price increases with the distance of the destination market. The overall effect on f.o.b. prices depends on the trade-off between the negative direct effect distance exerts on f.o.b. prices and its positive effect through income.

\footnotetext{
18 This is a standard feature of vertical differentiation models, see Gabszewicz and Thisse (1979) or Wauthy (1996).

${ }^{19} \mathrm{~A}$ similar conclusion can be drawn by observing that the value of a country's export is positively related with the income of the country of destination and negatively related to its distance, see e.g. Bernard et al. (2007) for an analysis with US data.
} 


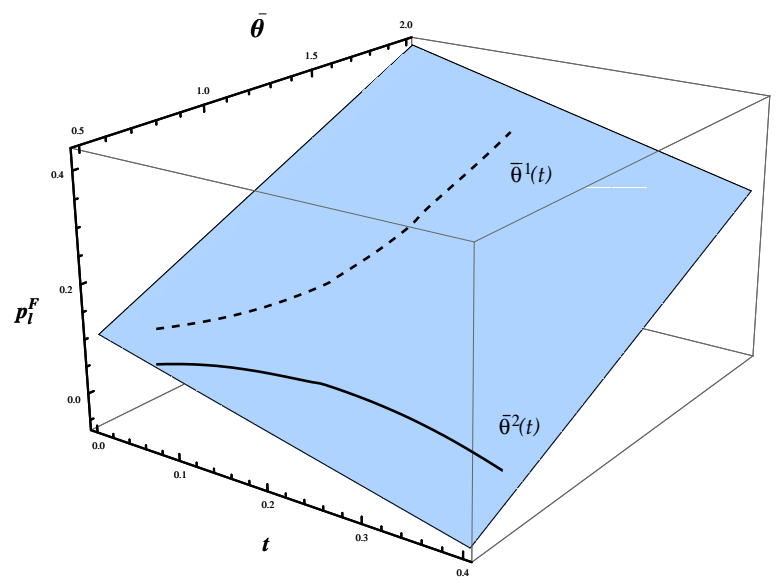

Figure 1: F.o.b. prices, income and distance.

Zeros and distance The last point has introduced another issue, which is empirically relevant, namely, that of trade zeros. Following the definition of (Baldwin and Harrigan, 2011, p. 16), a zero is "a trade flow which could have occurred but did not". Our model is in accordance with the factual evidence reported above on the positive relationship between the likelihood of zeros and the distance to the destination market. In fact Theorem 1 states that a duopoly equilibrium with two active firms exists only when trade costs are low enough $(t<\bar{t})$. When $t$ is large there is no duopoly equilibrium with two active firms and thus no trade. Furthermore, as noted above, for given qualities, the higher $t$ is, the less likely the condition ensuring that second-stage prices are positive (see Remarks 1 and 2.) Although comparative statics cannot be performed on the value of $\bar{t}$, numerical exercises suggest that this cutoff value is increasing with $\bar{u}$, the upper bound of the feasible quality spectrum. This is in accordance with common sense: the wider the range is over which qualities can be selected, the easier it is to "relax price competition through product differentiation", ${ }^{20}$ and thus the larger the distance compatible with viable trade. Stated differently, the wider the technical capacity to differentiate products within the industry, the more distant the trading partners can be. Finally, notice that the capacity to differentiate, as summarized by $\bar{u}$ also influences the equilibrium configuration. It is easy to ascertain that $\tilde{t}$ is increasing in $\bar{u}$ : for given $t$, the wider the feasible quality range, the larger the parameter region is where the foreign firm may be the quality leader.

Trade policy Recent trade literature has started to explore strategic trade policies in markets with vertical differentiation (see, e.g., Herguera et al. 2000, 2002 and Boccard and Wauthy 2005). This literature has focused on the phenomenon of quality reversal which occurs when, in a set-up of vertical product differentiation, a trade policy reverses the equilibrium ranking of qualities. These papers show that, in trade models with endogenous quality, there are large incentives for lagging industries to reverse the situation to their advantage. A trade

\footnotetext{
${ }^{20}$ Gabszewicz and Thisse (1979); Shaked and Sutton (1982).
} 
policy may, in fact, induce a quality reversal that turns the domestic producer into a quality leader in the market: in such a case, the domestic firm's profits and, consequently, the domestic welfare increase. As shown in Theorem 1, in our model distance may lead to a reversal of the quality ranking. Because of transport costs, in fact, the domestic firm can credibly commit to begin a price-war with the foreign firm, even if the latter sells initially the best available quality. When $\tilde{t} \leq t<\bar{t}$, distance makes the domestic firm be more aggressive at the quality stage, with the foreign firm that can only accommodate with a low-quality good. Our model thus suggests that trade policy has a scope that is limited geographically to neighboring countries; when trade partners are distant, it is strategic interaction itself that induces the domestic producer to become of high quality.

\section{Extensions}

The present model is built on the easiest case of two single-product firms and focuses on the trade flow from a "foreign" firm to the "domestic" destination market where consumers reside and another producer is settled. This section discusses some possible extensions.

Two-way trade flows and asymmetric trade costs. A straightforward extension consists of modeling consumers in the "foreign" location as well, and to allow firms to produce one variant of the good for each market (that is, to let firms design "domestic" and "export" versions of the good) and to compete in both. In this way, the model would be a full-fledged intra-industry trade model. When distance is not prohibitively high $(t<\bar{t})$, two-way trade flows will emerge at equilibrium. If arbitrage is excluded, the model's outcomes should be similar to those of Theorem 1, with each firm being a high- or low-quality producer on each market for $t \in[0, \tilde{t}]$, but playing the role of high-quality producer for the domestic market and low-quality exporter for the other for $t \in[\tilde{t}, \bar{t}]$. Similarly, by reverting to the interpretation of $t$ as a generic trade cost, including distance as well as any other obstacle to trade, asymmetric unit trade costs can be taken into account, say, $t^{F}$ from the Domestic to the Foreign country and $t^{D}$ from country $F$ to $D$. In this case, we would obtain parameter regions in the $t^{F}$ and $t^{D}$ segments similar to those in Propositions 1 and 3. By combining them, one would obtain the equivalent of Theorem 1. In all cases the quality of the low-quality good should increase with the distance of the destination market, as in Theorem 2. Thus, a result in line with Corollary 1 should hold as well. A similar outcome should be obtained if transport costs were the same for any trade direction but consumers had different incomes. Similarly, if there were more than two countries, and each firm were still restricted to ship one variant only to each market, one should expect that the quality of the good shipped by each firm to each destination should increase with its distance, as long as trade costs allow for viable trade.

Whereas the extension to intra-industry trade with firms producing a single variant for each market is straightforward, accounting for firms producing many variants for each market would be more problematic (see, e.g. Bernard et al. 2010; Eckel and Neary 2010). Indeed, in this case, domestic firms may use non-price competition in the form of product proliferation to limit, if not blockade at all, entry of foreign firms (see Gabszewicz and Thisse 1980 or De Fraja 1996 for example). The domestic incumbent may try to fill in the lower-quality product 
niches to leave no room in the product space for potential foreign entrants, at the cost of a partial self-cannibalization. Clearly, the effectiveness of this instrument may be reduced by the presence of costs of product development, but the incentive for firms to use their product range as an anti-competitive device may substantially modify the analysis.

Many firms Another possible extension considers maintaining the focus on country $D$ and assumes that many single-product firms may operate there, some being settled in $D$ and others exporting their product from $F$. In this case, the equilibrium quality specialization pattern of firms (which firm is the top quality producer, which is the next, and so on) would be much more complicated than that found in this paper. ${ }^{21}$ It is reasonable to conjecture, however, that in such a model there would be (i) a cutoff value for distance above which no trade would be observed and (ii) another threshold above which the top quality producer(s) is local and the quality followers are foreign. Also, in this case, a (negative) relationship between distance and the probability of finding foreign producers among the "quality leaders" should emerge. Finally, it is reasonable to think that the effect of distance on the quality level of goods should remain unchanged.

Production costs Our analysis abstracts from any supply-side features. Fixed production costs do not modify firm's pricing and quality design decisions and thus would leave our results qualitatively unchanged. Similarly, introducing symmetric marginal production costs should not modify the main outcomes of our paper. By contrast, if production costs are qualitydependent, a large difference between the production costs of the high-quality variant and that of the low-quality one may prevent the foreign firm from becoming the high-quality producer, such that only part $(i i)$ of Theorem 1 would still hold at equilibrium. A result in line with Theorem 2 should hold in this case.

On the other hand, a costly product design would have, as a first effect, that the highquality producer would possibly not select the high-end of the quality spectrum. Furthermore, if quality adjustment costs increase "too rapidly" in quality, then each firm may prefer to supply the low-quality variant instead of aiming at being the quality leader. This would invalidate our results. By contrast, if these costs are not "too convex", then the mechanism we have highlighted in this paper should still be present and should be included among the forces governing equilibrium outcomes.

\section{Conclusion}

This paper contributes to the vast and growing literature on trade and quality by identifying a mechanism explaining the observed increase in unit values (and thus quality) with the distance of the country of shipping. This mechanism, which complements the ones that are usually reckoned as shaping quality-differentiated trade flows, acts through the effect of distance on the strategic behavior of firms when quality is a choice variable for oligopolistic firms. In fact, the literature usually seeks the determinants of firms' specialization, trade viability and

\footnotetext{
${ }^{21}$ Indeed, to the best of our knowledge, no paper has completely characterized the equilibrium of a game of quality choice and price setting with more than two firms, not even with competition restricted to domestic firms.
} 
trade flow characteristics among ex ante productivity (broadly speaking) and/or preference differences between firms and countries. In contrast, by removing any ex ante asymmetry (except location) between trading partners, we have delved into the interaction of distance and strategic behavior in determining both the roles (high- versus low-quality producer) of domestic and foreign firms and the effects of distance on quality-differentiated trade flows. In particular, we have analyzed the relationship between trade, quality and distance by means of a parsimonious trade model with endogenous quality choice and oligopolistic competition. We have modeled the interaction between firms as a two-stage game (quality design, then price-setting) with simultaneous moves at each stage. We have identified the conditions under which trade is viable and have characterized the subgame-perfect Nash equilibrium of such a game. Our main result is that distance unambiguously increases the average quality level of the traded good. This is in accordance with recent empirical findings on the relationship between the quality of traded goods and the distance of the country of destination. Also, by accounting for income variability, our model provides insights on the behavior of f.o.b. prices with respect to distance of the trading partner. 


\section{A Proof of Proposition 1}

We prove Proposition 1 through a series of lemmata.

Lemma 2. Let $u_{h}^{D} \geq u_{l}^{F}$, then the unique maximizer of $\hat{\pi}\left(u_{h}^{D}\right)$ is $u_{h}^{D *}=\bar{u}$.

Proof. (i) Consider the range $\left.\left.u_{h}^{D} \in\right] \frac{u_{l}^{F}\left(u_{l}^{F}-t\right)}{u_{l}^{F}-2 t}, \bar{u}\right]$ first. In this case the market structure is duopolistic and second stage profits are the same as in (4). The partial derivative of $\hat{\pi}_{h}\left(u_{h}^{D}\right)$ w.r.t. $u_{h}^{D}$ is

$$
\frac{\partial \hat{\pi}_{h}^{D}}{\partial u_{h}^{D}}=\frac{u_{h}^{D}\left(t+2 u_{h}^{D}-2 u_{l}^{F}\right) f\left(u_{h}^{D}\right)}{\left(u_{h}^{D}-u_{l}^{F}\right)^{2}\left(4 u_{h}^{D}-u_{l}^{F}\right)^{3}}
$$

where

$$
f\left(u_{h}^{D}\right)=\left[8\left(u_{h}^{D}\right)^{3}-\left(u_{h}^{D}\right)^{2}\left(4 t+14 u_{l}^{F}\right)-u_{h}^{D} u_{l}^{F} t-10 u_{h}^{D}\left(u_{l}^{F}\right)^{2}-4\left(u_{l}^{F}\right)^{3}+2\left(u_{l}^{F}\right)^{2} t\right]
$$

The denominator and the first two terms of the numerator are positive. Our task is therefore to prove that the polynomial $f\left(u_{h}^{D}\right)$ is positive. Notice that $f\left(\frac{u_{l}^{F}\left(u_{l}^{F}-t\right)}{u_{l}^{F}-2 t}\right)>0$. Consider now the first-order derivative of (13)

$$
f^{\prime}\left(u_{h}^{D}\right)=24\left(u_{h}^{D}\right)^{2}-4\left(2 t+7 u_{l}^{F}\right) u_{h}^{D}-\left(t-10 u_{l}^{F}\right) u_{l}^{F} .
$$

It can be proven that for all $u_{h}^{D} \geq \frac{u_{l}^{F}\left(u_{l}^{F}-t\right)}{u_{l}^{F}-2 t}$ this expression is positive, and thus so is $f\left(u_{h}^{D}\right)$. This implies that (12) is positive for all $\left.\left.u_{h} \in\right] \frac{u_{l}^{F}\left(u_{l}^{F}-t\right)}{u_{l}^{F}-2 t}, \bar{u}\right]$ and ultimately that the profit-maximizing quality is $\bar{u}$.

(ii) Consider now the interval $\left[u_{l}^{F}, \frac{u_{l}^{F}\left(u_{l}^{F}-t\right)}{u_{l}^{F}-2 t}\right]$. In this case, both the price and the demand of the foreign low-quality firm are zero under the pricing rules (5), thus (2) no longer defines the demand system. The price charged by the domestic high-quality firm is then its best reply at the second stage against the foreign low-quality firm setting a zero price, namely, $\tilde{p}_{h}^{D}\left(u_{h}^{D}, u_{l}^{F}\right)=\frac{1}{2}\left(u_{h}^{D}-u_{l}^{F}+t\right)$, and its profits are $\tilde{\pi}_{h}^{D}\left(u_{h}^{D}, u_{l}^{F}\right)=\tilde{p}_{h}^{D}(\cdot)\left(1-\frac{\tilde{p}_{h}^{D}(\cdot)-t}{u_{h}^{D}-u_{l}^{F}}\right)$. It is then a matter of simple calculations to ascertain that $\tilde{\pi}_{h}^{D}$ is maximized for $u_{h}^{D}=$ $\frac{u_{l}^{F}\left(u_{l}^{F}-t\right)}{u_{l}^{F}-2 t}$.

(iii) It is easy to show that for all $\bar{u}$

$$
\tilde{\pi}_{h}^{D}\left[\frac{u_{l}^{F}\left(u_{l}^{F}-t\right)}{u_{l}^{F}-2 t}\right]<\hat{\pi}_{h}^{D}(\bar{u})
$$

(iv) Notice that if $u_{h}^{D}=u_{l}^{F}$, the good is homogeneous and thus equations in (2) no longer represent demands. In this case the price of the domestic high-quality good is $t-\varepsilon$, while that of the foreign low-quality one is zero. At these prices the demand of the foreign good is zero, while the one of the domestic firm is $1-\frac{t-\varepsilon}{u_{l}^{F}}$. Accordingly, its profits are $\left(1-\frac{t-\varepsilon}{u_{l}^{F}}\right)(t-\varepsilon)$. It is easily ascertained that this level of profits falls short of $\hat{\pi}_{h}^{D}(\bar{u})$.

We now consider the low-quality firm. We state the following:

Lemma 3. Let $u_{h}^{D} \geq u_{l}^{F}$, then there exists a unique $\left.\bar{t} \in\right] 0, u_{l}^{F}[$ such that for all $t<\bar{t}$ the unique maximizer of $\left.\hat{\pi}_{l}^{F}(\cdot), u_{l}^{F *}\left(u_{h}^{D}\right) \in\right] 0, u_{h}^{D}[$. 
Proof. (i) Assume that $u_{l}^{F}<u_{h}^{D}$ first and consider the derivative of $\hat{\pi}_{l}^{F}$ w.r.t. $u_{l}^{F}$.

$$
\frac{\partial \hat{\pi}_{l}^{F}}{\partial u_{l}^{F}}=-\frac{u_{h}^{D}\left[u_{l}^{F}-u_{l}^{F}\left(t+u_{h}^{D}\right)+2 t u_{h}^{D}\right] g\left(u_{l}^{F}\right)}{u_{l}^{F^{2}}\left(u_{h}^{D}-u_{l}^{F}\right)^{2}\left(4 u_{h}^{D}-u_{l}^{F}\right)^{3}},
$$

where

$g\left(u_{l}^{F}\right) \equiv\left[\left(u_{l}^{F}\right)^{3}\left(7 u_{h}^{D}-2 t\right)+\left(u_{l}^{F}\right)^{2}\left[9 t u_{h}^{D}-11\left(u_{h}^{D}\right)^{2}\right]+u_{l}^{F}\left(4\left(u_{h}^{D}\right)^{3}-18 t\left(u_{h}^{D}\right)^{2}\right)+8 t u_{h}^{D^{3}}\right]$.

First of all notice, that over the relevant interval $\left[0, u_{h}^{D}\right.$ [ the derivative (14) is continuous in $u_{l}^{F}$. Second, notice that concavity of (14) with respect to $u_{l}^{F}$ requires that $t<\bar{t}$, with $0<\bar{t}<u_{l}^{F} .^{22}$ We now proceed by finding the zeros of (14). This function has five roots, namely, the two zeros of the first term at the numerator, and three zeros of $g\left(u_{l}^{F}\right)$. The roots of the first term are real, but they can be disregarded as candidate maximizers because, although lying in the interval $\left[0, u_{h}^{D}\right]$, they do not fulfill local secondorder conditions and in correspondence to these values $\hat{\pi}_{l}^{F}(\cdot)=0 .{ }^{23}$ Consider now the remaining factor, the polynomial function $g\left(u_{l}^{F}\right)$, which is a one-parameter family of cubics depending on $t>0$. First, note that $g(0)=8 t\left(u_{h}^{D}\right)^{3}>0$. Since $\lim _{u_{l}^{F} \rightarrow-\infty} g(\cdot)=$ $-\infty$, this implies that $g\left(u_{l}^{F}\right)$ and consequently (14) admits a negative real root. In the following, we prove that $g(\cdot)$ admits two further real roots for every value of $t>0$, but only one of them belongs to the relevant interval $\left[0, \bar{u}_{h}^{D}[\right.$, whereas the other one is necessarily larger than $u_{h}^{D}$ and thus not acceptable. To show this, notice that $g\left(u_{h}^{D}\right)=$ $-3 t\left(u_{h}^{D}\right)^{3}<0$ and $\lim _{u_{l}^{F} \rightarrow \infty} g(\cdot)=\infty$. By continuity, the function $g(\cdot)$ (and thus (14)) must cross the real axis at a value larger than $u_{h}^{D}$. As noted above this root is not acceptable. Consequently there exists another value $\left.u_{l}^{F *} \in\right] 0, u_{h}^{D}\left[\operatorname{such}\right.$ that $g\left(u_{l}^{F *}\right)=$ $\frac{\partial \hat{\pi}_{l}^{F}\left(u_{l}^{F *}, u_{h}^{D}\right)}{\partial u_{l}^{F}}=0$. Since the solutions to the first term of (14) are internal to $\left[0, u_{h}^{D}\right]$ and correspond to local minima, the solution $u_{l}^{F *}\left(u_{h}^{D}\right)$ lies between them and is a local maximum for all $t \in[0, \bar{t}]$.

(ii) Assume now that $u_{l}^{F}=u_{h}^{D}$. In this case, (2) is no longer the demand system because price competition with a homogeneous good triggers a Bertrand war. It is straightforward to ascertain that, in this case, the optimal price of the high-quality firm is $t-\varepsilon$ and that of the low-quality one is 0 . Consequently, no consumer patronizes the foreign producer, and thus its profits are zero.

Lemma 4. There exists a unique cutoff $\tilde{u}>u_{l}$ such that for all the $\bar{u}>\tilde{u}$, the pair $\left(\bar{u}, \underline{u}^{F}\right)$, where $\underline{u}^{F} \equiv u_{l}^{F *}(\bar{u})$, is a couple of mutual best replies at the quality-choice stage of game $\Gamma$ for the domestic and foreign firms, respectively, and thus they are the quality levels chosen at a subgame-perfect Nash equilibrium of this game.

Proof. The proof of this lemma requires that no firm has a profitable deviation from the

\footnotetext{
${ }^{22}$ The cumbersome expression of $\bar{t}$ is available upon request.

${ }^{23}$ Calculations are available upon request.
} 
candidate equilibrium strategies $\bar{u}$ for the $D$ firm and $\underline{u}^{F}$ for the $F$-firm ${ }^{24}$. Note that the robustness of these strategies has to be checked against unilateral deviations in the whole strategy space, not only in that defined by case (i). In other words, to demonstrate Lemma 3 we need to show that no firm wants to leapfrog its rival (see, for example, Motta et al. 1997).

(i) Consider firm $D$ first. We need to prove that this firm has no profitable deviations from $(\bar{u})$ when its rival plays $\left(\underline{u}^{F}\right)$. Clearly, the only strategy (sub-)space where deviations have to be looked for is $\left[0, \underline{u}^{F}\right]$. In this case, the actual high-quality producer is the foreign firm, while the domestic one plays the role of the low-quality producer. Thus we need to re-define firm $D$ 's profits to take into account this fact. Let $u_{\mathcal{L}}^{D} \in\left[0, \underline{u}^{F}\right]$ and $p_{\mathcal{L}}^{D}$ be the quality level and the price firm $D$ deviates to. Accordingly, let its deviation demand be $\mathrm{e}^{25}$

$$
\mathcal{D}_{\mathcal{L}}^{D}=\frac{\hat{p}_{l}^{F}(\cdot)+t-p_{\mathcal{L}}^{D}}{\underline{u}^{F}-u_{\mathcal{L}}^{D}}-\frac{p_{\mathcal{L}}^{D}}{u_{\mathcal{L}}^{D}}
$$

Thus the deviation profits are

$$
\pi_{\mathcal{L}}^{D}=p_{\mathcal{L}}^{D}\left[\frac{\hat{p}_{l}^{F}(\cdot)+t-p_{\mathcal{L}}^{D}}{\underline{u}^{F}-u_{\mathcal{L}}^{D}}-\frac{p_{\mathcal{L}}^{D}}{u_{\mathcal{L}}^{D}}\right] .
$$

Simple calculations show that there exists a unique price that maximizes (16), namely, $\hat{p}_{\mathcal{L}}^{D}=\frac{u_{\mathcal{L}}^{D}\left[2 t \bar{u}+\bar{u}_{\underline{u}}^{F}-\left(\underline{u}^{F}\right)^{2}\right]}{2 \underline{u}^{F}\left(4 \bar{u}-\underline{u}^{F}\right)}$, which can be plugged back into (16) to obtain the expression for the deviation profits as a function of quality levels only:

$$
\hat{\pi}_{\mathcal{L}}^{D}\left(u_{\mathcal{L}}^{D}, \bar{u}, \underline{u}^{F}\right)=\frac{\left[2 t \bar{u}+\left(\bar{u}-\underline{u}^{F}\right) \underline{u}^{F}\right]^{2} u_{\mathcal{L}}^{D}}{4 \underline{u}^{F}\left(4 \bar{u}-\underline{u}^{F}\right)^{2}\left(\underline{u}^{F}-u_{\mathcal{L}}^{D}\right)} .
$$

It can be proved that the demand $\mathcal{D}_{\mathcal{L}}^{D}$ is always increasing in $u_{\mathcal{L}}^{D}$, but its upper bound stops growing as $u_{\mathcal{L}}^{D}$ hits $\hat{u}_{\mathcal{L}}^{D}=\frac{2 \bar{u} \underline{u}^{F}\left[3 u^{F}-2 t\right]}{\underline{u}^{F}\left[7 \bar{u}-\underline{u}^{F}\right]-2 t \bar{u}}<\underline{u}^{F}$. For all $u_{\mathcal{L}}^{D} \in\left[\hat{u}_{\mathcal{L}}^{D}, \underline{u}^{F}\right]$, the deviating firm's profit is $\left(1-\frac{\hat{p}_{\mathcal{L}}^{D}}{u_{\mathcal{L}}^{D}}\right) p_{\mathcal{L}}^{D}$, which is always increasing in $u_{\mathcal{L}}^{D}$, and thus the profit-maximizing quality level is $\underline{u}^{F}{ }^{26}$ The corresponding profit is:

$$
\hat{\pi}_{\mathcal{L}}^{D}\left(u_{\mathcal{L}}^{D *}, \bar{u}, \underline{u}^{F}\right)=\pi_{\mathcal{L}}^{D *}\left(\bar{u}, \underline{u}^{F}\right)=\frac{\bar{u}\left[\underline{u}^{F}\left(7 \bar{u}-\underline{u}^{F}\right)-2 t \bar{u}\right]\left[\underline{u}^{F}\left(\bar{u}-\underline{u}^{F}\right)+2 t \bar{u}\right]}{4 \underline{u}^{F}\left(4 \bar{u}-\underline{u}^{F}\right)^{2}} .
$$

Direct comparison of $\hat{\pi}_{h}^{D}\left(\bar{u}, \underline{u}^{F}\right)$ and $\pi_{\mathcal{L}}^{D *}\left(\bar{u}, \underline{u}^{F}\right)$ indicates that

$$
\hat{\pi}_{h}^{D}\left(\bar{u}, \underline{u}^{F}\right)>\pi_{\mathcal{L}}^{D *}\left(\bar{u}, \underline{u}^{F}\right) .
$$

In principle, there is another possible deviation available to the domestic firm, namely, to set $u_{\mathcal{L}}^{D}=\underline{u}^{F}$ and $p_{\mathcal{L}}^{D}=\hat{p}_{l}^{F}\left(\bar{u}, \underline{u}^{F}\right)+t-\varepsilon$. It can be proven, however, that the profit

\footnotetext{
${ }^{24}$ Recall that we summarize firms' strategies by reporting optimal qualities only, $\left(\hat{p}_{j}^{i}, u_{j}^{i *}\right)$ is represented by $\left(u_{j}^{i *}(\bar{u})\right)$.

${ }^{25}$ The demand is as in (16) as long as $p_{\mathcal{L}}^{D}$ and $u_{\mathcal{L}}^{D}$ are such that $\frac{\hat{p}_{l}^{F}(\cdot)+t-p_{\mathcal{L}}^{D}}{\underline{u}^{F}-u_{\mathcal{L}}^{D}}<1$. If $\frac{\hat{p}_{l}^{F}(\cdot)+t-p_{\mathcal{L}}^{D}}{\underline{u}^{F}-u_{\mathcal{L}}^{D}} \geq 1$ then the demand is $1-\frac{p_{\mathcal{L}}^{D}}{u_{\mathcal{L}}^{D}}$.

${ }^{26}$ Notice that a Bertrand war is avoided here because the lower bound to the foreign good price is equal to $t$, the transport cost. Furthermore, at the optimal deviation quality the condition defined by Remark 1 is not met. Thus the demand for the foreign good goes down to zero, and the market is solely served by the deviating firm.
} 
earned in this case never exceeds $\hat{\pi}_{h}^{D}\left(\bar{u}, \underline{u}^{F}\right)$ as long as $\bar{u}>\tilde{u}$. Thus, we conclude that there exists no profitable deviation from $\bar{u}$ for firm $D$ when firm $F$ selects $\underline{u}^{F}$.

(ii) Firm $F$ has no profitable deviation for $u_{l}^{F}<\bar{u}$, because $\underline{u}^{F}$ is the unique profit maximizer for all $u_{l}^{F}<u_{h}^{D}$, and, by construction, it cannot deviate to a quality higher than $\bar{u}$, the maximum level of the quality spectrum. Finally, a deviation to $\bar{u}$ is not profitable because it would entail a price war over a homogeneous good.

Proposition 1 is obtained by combining the results of Lemmata 2-4.

\section{B Proof of Proposition 2}

Although we are able to compute explicitly the equilibrium value for $u_{l}^{F}$, this turns out to be exceedingly cumbersome and thus not very informative. ${ }^{27}$ We shall therefore perform comparative statics analysis by means of indirect methods.

As a general remark, notice that $\bar{t}<\frac{\underline{u}^{F}}{2}$.

(i) Consider the function $g\left(u_{l}^{F}\right)$ defined in Lemma 3:

$$
g\left(u_{l}^{F}\right)=\left(u_{l}^{F}\right)^{3}(7 \bar{u}-2 t)+\left(u_{l}^{F}\right)^{2}\left[9 t \bar{u}-11(\bar{u})^{2}\right]+u_{l}^{F}\left(4(\bar{u})^{3}-18 t(\bar{u})^{2}\right)+8 t \bar{u}^{3},
$$

within the interval $\left[\frac{4}{7} \bar{u}, \frac{29}{49} \bar{u}\right]$. At the left-end boundary of the interval the function's value is $g\left(\frac{4}{7} \bar{u}\right)=\frac{96 t \bar{u}^{3}}{343}>0$, while at the right-end its value is

$$
g\left(\frac{29}{49} \bar{u}\right)=\frac{(9973 t-4060 \bar{u}) \bar{u}^{3}}{117649} .
$$

Notice, however, that the restriction $t<\frac{u_{l}^{F}}{2}$ implies $t<\frac{29 \bar{u}}{98}$, and thus the value of $g\left(\frac{29}{49} \bar{u}\right)$ can be evaluated as

$$
\frac{(9973 t-4060 \bar{u}) \bar{u}^{3}}{117649}<-\frac{108663}{11529602} \bar{u}^{4}<0 .
$$

By continuity, the relevant root of $g\left(u_{l}^{F}\right)$, that is, the optimal strategy for the foreign firm, belongs to the interval $\left(\frac{4}{7} \bar{u}, \frac{29}{49} \bar{u}\right)$.

(ii) Consider $g\left(u_{l}^{F}, t\right)$ as a two-variable function of $u_{l}^{F}$ and $t$, restricted to the domain $\left[\frac{4}{7} \bar{u}, \frac{29}{49} \bar{u}\right] \times\left[0, \frac{29}{98} \bar{u}\right]$. By the Implicit Function Theorem, in this domain there exists a $C^{1}$ function $\underline{u}^{F}(t)$ such that:

$$
\underline{u}^{F \prime}(t)=-\frac{\frac{\partial g}{\partial t}}{\frac{\partial g}{\partial \underline{u}^{F}}}=\frac{2\left(\underline{u}^{F}\right)^{3}-9 \bar{u}\left(\underline{u}^{F}\right)^{2}+18 \bar{u}^{2} \underline{u}^{F}-8 \bar{u}^{3}}{3(7 \bar{u}-2 t)\left(\underline{u}^{F}\right)^{2}+2\left(9 t \bar{u}-11 \bar{u}^{2}\right) \underline{u}^{F}+4 \bar{u}^{3}-18 t \bar{u}^{2}} .
$$

\footnotetext{
${ }^{27}$ The value of $\underline{u}^{F}$ is available upon request from the authors.
} 
To evaluate the sign of (20) consider first the function at the numerator

$$
N\left(\underline{u}^{F}\right)=2\left(\underline{u}^{F}\right)^{3}-9 \bar{u}\left(\underline{u}^{F}\right)^{2}+18 \bar{u}^{2} \underline{u}^{F}-8 \bar{u}^{3} .
$$

Notice that $N\left(\frac{4}{7} \bar{u}\right)=-\frac{96 \bar{u}^{3}}{343}, N\left(\frac{29}{49} \bar{u}\right)=-\frac{3084 \bar{u}^{3}}{15625}$, and since

$$
N^{\prime}\left(\underline{u}^{F}\right)=6\left[\left(\underline{u}^{F}\right)^{2}-3 \bar{u} \underline{u}^{F}+6 \bar{u}^{2}\right]>0
$$

we conclude that $N\left(\underline{u}^{F}\right)$ is monotonically increasing and negative in the whole domain $\left[\frac{4}{7} \bar{u}, \frac{29}{49} \bar{u}\right]$.

Move now to the function at the denominator

$$
D\left(\underline{u}^{F}, t\right)=3(7 \bar{u}-2 t)\left(\underline{u}^{F}\right)^{2}+2\left(9 t \bar{u}-11 \bar{u}^{2}\right) \underline{u}^{F}+4 \bar{u}^{3}-18 t \bar{u}^{2} .
$$

Since $\frac{\partial D}{\partial t}<0$ for every admissible $\underline{u}^{F}$, the gradient of $D(\cdot)$ never vanishes in the rectangle under scrutiny, hence we evaluate the function at its boundary to establish whether it may change its sign.

Firstly the evaluation of $D(\cdot)$ at the boundaries for the choice variable yields:

$$
\begin{array}{r}
D\left(\frac{4}{7} \bar{u}, t\right)=-42(79 t+14 \bar{u}) \bar{u}^{2}<0, \\
D\left(\frac{29}{49} \bar{u}, t\right)=-49(22686 t+3997 \bar{u}) \bar{u}^{2}<0,
\end{array}
$$

for all values of $t$.

Secondly the evaluation of $D(\cdot)$ at the boundaries for the unit transport cost returns:

$$
D\left(\underline{u}^{F}, 0\right)=\bar{u}\left[21\left(\underline{u}^{F}\right)^{2}-22 \underline{u}^{F} \bar{u}+4 \bar{u}^{2}\right]<-\frac{417}{343} \bar{u}^{3}<0,
$$

and

$$
\begin{aligned}
& D\left(\underline{u}^{F}, \frac{29}{98} \bar{u}\right)=-\frac{\bar{u}}{49}\left(65 \bar{u}^{2}+817 \bar{u} \underline{u}^{F}-942\left(\underline{u}^{F}\right)^{2}\right)< \\
&<-\frac{\bar{u}}{49}\left(65 \bar{u}^{2}+\frac{13237}{29}\left(\underline{u}^{F}\right)^{2}\right)<0 .
\end{aligned}
$$

Since $D(\cdot)$ is negative on the boundary of the rectangle and has no stationary points inside it, its negativity over the whole rectangle is ensured. Then, we conclude that the sign of (20) is positive.

\section{Proof of Proposition 3}

Similarly to the proof of Proposition 1, we proceed by demonstrating a series of Lemmata.

Lemma 5. Let $u_{l}^{D} \leq u_{h}^{F}$ and $\bar{u}>\frac{1}{2}\left(t+u_{l}^{D}+\sqrt{t^{2}+\left(u_{l}^{D}\right)^{2}}\right) \equiv \hat{u}$, then the unique maximizer of $\pi_{h}^{F}$ is $\bar{u}$. 
Proof. First of all recall (see Remark 2) that, if $\bar{u} \leq \hat{u}$, there is no quality level along the feasible quality spectrum for the foreign firm compatible with a positive demand. Remark 2 implies also that if $\bar{u}<\hat{u}$, the foreign firm cannot optimally select any quality level below $\hat{u}$ because this would entail a zero demand. Focus therefore on the interval $\left.u_{h}^{F} \in\right] \hat{u}, \bar{u}$ ] and consider now the partial derivative of the foreign firm's profits w.r.t. $u_{h}^{F}$ :

$$
\frac{\partial \pi_{h}^{F}}{\partial u_{h}^{F}}=\frac{h\left(u_{h}^{F}\right)\left[2 u_{h}^{F}\left(u_{h}^{F}-u_{l}^{D}\right)-t\left(2 u_{h}^{F}-u_{l}^{D}\right)\right]}{\left(u_{h}^{F}-u_{l}^{D}\right)^{2}\left(4 u_{h}^{F}-u_{l}^{D}\right)^{3}},
$$

where

$$
h\left(u_{h}^{F}\right)=8\left(u_{h}^{F}\right)^{2}\left(t+u_{h}^{F}\right)+5\left(u_{l}^{D}\right)^{2}\left(t+2 u_{h}^{F}\right)-2 u_{h}^{F} u_{l}^{D}\left(5 t+7 u_{h}^{F}\right)-4\left(u_{l}^{D}\right)^{3} .
$$

Notice that the denominator of (21) is positive for all $u_{l}^{D}<u_{h}^{F}$ and that the term within square brackets at the numerator is positive when $u_{h}^{F}>\hat{u}$. Move now to the polynomial (22), it can be ascertained that $h\left(u_{h}^{F}\right)>0$. Consider now the partial derivative $h^{\prime}\left(u_{h}^{F}\right)$. Standard computations show that $h^{\prime}(\cdot)>0 \forall u_{h}^{F}>u_{l}^{D}$. Thus, maximization of $\hat{\pi}_{l}^{F}(\cdot)$ requires the foreign firm to hit the upper bound of the quality spectrum.

Lemma 6. Let $u_{l}^{D} \leq u_{h}^{F}$, then (i) if $t<\tilde{t}$ there exists a unique maximizer of $\hat{\pi}_{l}^{D}, u_{l}^{D *}\left(u_{h}^{F}\right) \in$ ] $0, u_{h}^{F}\left[\right.$; (ii) if $t \geq \tilde{t}$ the unique maximizer of $\hat{\pi}_{l}^{D}$ is $u_{h}^{F}$.

Proof. (i) Assume $u_{l}^{D}<u_{h}^{F}$ and $t<\frac{u_{h}^{F}}{11}$. Consider the partial derivative

$$
\frac{\partial \hat{\pi}_{l}^{D}(\cdot)}{\partial u_{l}^{D}}=\frac{u_{h}^{F}\left(t+u_{h}^{F}-u_{l}^{D}\right) m\left(u_{l}^{D}\right)}{\left(u_{h}^{F}-u_{l}^{D}\right)^{2}\left(4 u_{h}^{F}-u_{l}^{D}\right)^{3}},
$$

where $m\left(u_{l}^{D}\right) \equiv\left(u_{l}^{D}\right)^{2}\left(7 u_{h}^{F}-2 t\right)+u_{h}^{F} u_{l}^{D}\left(t-11 u_{h}^{F}\right)+4\left(u_{h}^{F}\right)^{2}\left(t+u_{h}^{F}\right)$.

The denominator and the first term of the numerator are positive as long as $u_{l}^{D}<u_{h}^{F}$. Thus we focus on the polynomial $m(\cdot)$. This function has two real roots within the interval $] 0, u_{h}^{F}$ [ as long as $t<\frac{u_{h}^{F}}{11}$. Furthermore, only one of these roots satisfies the second-order condition for a maximum. Label this solution $u_{h}^{F *}\left(u_{l}^{D}\right)$.

(ii) Keep assuming that $u_{l}^{D}<u_{h}^{F}$ but move now to the case $t \geq \frac{u_{h}^{F}}{11}$. In this case, (23) has no real roots within $] 0, u_{h}^{F}$ [, and it is always increasing over this interval. Thus the domestic firm finds it profitable to increase its product's quality as much as possible, in principle, up to $u_{h}^{F}$. This would eventually violate the condition reported in Remark 2. However it can be easily ascertained that as the quality of the domestic firm rises to $u_{h}^{F}$, its demand increases while the optimal price decreases. The demand stops growing as the condition in Remark 2 is met. Any further increase in $u_{l}^{D}$ would entail no increase in the demand but a reduction in the optimal price, resulting in a profit loss. These observations allow us to conclude that, in this case, the profit-maximizing quality level is $u_{l}^{D}=\frac{2 u_{h}^{F}\left(u_{h}^{F}-t\right)}{2 u_{h}^{F}-t}<u_{h}^{F}$.

Finally consider the situation $u_{l}^{D}=u_{h}^{F}$. In this case the good is homogeneous and, a price war arises. Again (2) is no longer the demand system. Optimal prices are thus $t-\varepsilon$, with $\varepsilon$ positive and arbitrarily small for the domestic firm and 0 for the foreign one. At these prices, the foreign producer has no demand, while that of the 
domestic firm is $1-\frac{t-\varepsilon}{u_{h}^{F}}$, such that its profits amount to $\tilde{\pi}_{l}^{D} \equiv\left(1-\frac{t-\varepsilon}{u_{h}^{F}}\right)(t-\varepsilon)$. It can be proved that, while $\tilde{\pi}_{l}^{D}>\hat{\pi}_{l}^{D}\left[\frac{2 u_{h}^{F}\left(u_{h}^{F}-t\right)}{2 u_{h}^{F}-t}\right], \tilde{\pi}_{l}^{D} \leq \hat{\pi}_{l}^{D}\left(u_{l}^{D *}\right) \Leftrightarrow t \in[0, \tilde{t}]$, where $\tilde{t}=\frac{u_{h}^{F}}{229}\left[137-\frac{1143^{2 / 3}}{\sqrt[3]{1131-458 \sqrt{6}}}-6 \sqrt[3]{3(1131-458 \sqrt{6})}\right] \approx \frac{3 u_{h}^{F}}{126}$.

Lemma 7. (i) Let $t<\tilde{t}$ and $\bar{u}>\hat{u}$. Then, the pair $\left(\bar{u}, \underline{u}^{D}\right)$, where $\underline{u}^{D} \equiv u_{l}^{D *}(\bar{u})$ is a couple of mutual best replies at the quality-choice stage of game $\Gamma$ for the domestic and foreign firms respectively. Thus they are the quality levels chosen at a subgame-perfect Nash equilibrium of this game. (ii) Let $t>\tilde{t}$ or $\bar{u}<\hat{u}$. Then there is no subgame-perfect Nash equilibrium of game $\Gamma$ with the domestic firm producing the low-quality good and the foreign firm supplying the high-quality one.

Proof. (i) It is necessary to show that there are no profitable unilateral deviations from $\left(\bar{u}, \underline{u}^{D}\right)$ in the strategy space. Because this proof parallels that of Lemma 4 , it will be just sketched. If the domestic low-quality producer leapfrogs downwards its rival, it finds it profitable to increase the quality of its variant up to $\underline{u}^{D}$. In this case, the good would be homogeneous, and thus the optimal price of the deviating firm would be $\hat{p}_{l}^{D}\left(\bar{u}, \underline{u}^{D}\right)-t-\varepsilon$. Accordingly, all of the demand would be served by the foreign firm. It is a matter of calculations to prove, however, that although positive, the deviation payoff is lower than that of the strategy under scrutiny. Thus the deviation is not profitable.

Consider now the domestic high-quality producer. From Lemma 6 we know that as long as $t<\tilde{t}$, the unique maximizer of the domestic firm's profits is $\underline{u}^{D} \in[0, \bar{u}]$. Deviations strictly above $\bar{u}$ are not admissible by construction.

(ii) From Lemma 6(ii)-(iii) it follows that if $t>\tilde{t}$, the domestic firm wants to deviate from the prescribed strategy $\underline{u}^{D}$ and set $u_{l}^{D}=\bar{u}$. Furthermore, if $\bar{u}<\hat{u}$, there is no quality level for the foreign firm compatible with a positive demand under duopoly pricing. This firm may therefore undercut its rival and become the low-quality producer earning positive profits (see Lemma 7 (i)). In both cases, $\left(\bar{u}, \underline{u}^{D}\right)$ cannot be an equilibrium.

The results of Lemmata 5 to 7 prove Proposition 3.

\section{Proof of Proposition 4}

The optimal quality level of the domestic firm is:

$$
\underline{u}^{D}(t)=\frac{\bar{u}\left(11 \bar{u}-t-\sqrt{9 \bar{u}^{2}-102 \bar{u} t+33 t^{2}}\right)}{14 \bar{u}-4 t} .
$$

It is easily ascertained that $\underline{u}^{D}(0)=\frac{4}{7} \bar{u}$ and $\underline{u}^{D}\left(\frac{\bar{u}}{11}\right)=\frac{4}{5} \bar{u}$. Moreover,

$$
\frac{\partial \underline{u}^{D}}{\partial t}=\frac{\bar{u}^{2}[15 \bar{u} \sqrt{(3 \bar{u}-t)(\bar{u}-11 t)}+\sqrt{3} \bar{u}(113 \bar{u}-43 t)]}{2 \bar{u}(7 \bar{u}-2 t)^{2} \sqrt{(3 \bar{u}-t)(\bar{u}-11 t)}}>0 \forall t<\frac{\bar{u}}{11} .
$$




\section{References}

Alchian, A. A. and Allen, W. R. (1964). University Economics. Wadsworth publishing company, Belmont (CA).

Altomonte, C., Colantone, I., and Pennings, E. (2010). "International Trade with Heterogenous Firms and Asymmetric Product Varieties". SSRN eLibrary.

Baldwin, R. and Harrigan, J. (2011). "Zeros, quality and space: trade theory and trade evidence". American Economic Journal: Microeconomics, 3(2):60-88.

Bastos, P. and Silva, J. (2010). "The quality of a firm's exports: Where you export to matters". Journal of International Economics, 82(2):99-111.

Bernard, A. B., Eaton, J., Jensen, J. B., and Kortum, S. (2003). "Plants and productivity in international trade". American Economic Review, 93(4):1268-1290.

Bernard, A. B., Jensen, J. B., Redding, S. J., and Schott, P. K. (2007). "Firms in international trade". Journal of Economic Perspectives, 21(3):105-130.

Bernard, A. B., Redding, S. J., and Schott, P. K. (2010). "Multiple-product firms and product switching". American Economic Review, 100(1):70-97.

Boccard, N. and Wauthy, X. (2005). "Enforcing domestic quality dominance through quotas*". Review of International Economics, 13(2):250-261.

Cabrales, A. and Motta, M. (2001). "Country asymmetries, endogenous product choice and the timing of trade liberalization". European Economic Review, 45(1):87-107.

Chaney, T. (2008). "Distorted gravity: the intensive and extensive margins of international trade". American Economic Review, 98(4):1707-1721.

Choi, C. J. and Shin, H. S. (1992). "A comment on a model of vertical product differentiation". Journal of Industrial Economics, 40(2):229-231.

Choi, Y. C., Hummels, D., and Xiang, C. (2006). "Explaining import variety and quality: The role of the income distribution". Working Paper 12531, National Bureau of Economic Research.

Crozet, M., Head, K. C., and Mayer, T. (2009). "Quality Sorting and Trade: Firm-Level Evidence for French Wine". SSRN eLibrary.

De Fraja, G. and Norman, G. (2004). "Product differentiation and the location of international production". Journal of Economics \& Management Strategy, 13(1):151-170.

De Fraja, G. (1996). "Product line competition in vertically differentiated markets". International Journal of Industrial Organization, 14(3):389-414.

Eaton, J. and Kierzkowski, H. (1984). "Oligopolistic competition, product variety, and international trade". In H. Kierzkowski, editor, "Monopolistic competition and international trade", pages 69-83. Clarendon Press. 
Eaton, J. and Kortum, S. (2002). "Technology, geography, and trade". Econometrica, 70(5):1741-1779.

Eckel, C. and Neary, J. P. (2010). "Multi-product firms and flexible manufacturing in the global economy". Review of Economic Studies, 77(1):188-217.

Flam, H. and Helpman, E. (1987). "Vertical product differentiation and north-south trade". The American Economic Review, 77(5):810-822.

Frascatore, M. (2001). "The influence of a neighbouring market on product qualities and prices". Australian Economic Papers, 40(3):287-306.

Gabszewicz, J. J. and Thisse, J.-F. (1979). "Price competition, quality and income disparities". Journal of Economic Theory, 20(3):340-359.

Gabszewicz, J. J. and Thisse, J.-F. (1980). "Entry (and exit) in a differentiated industry". Journal of Economic Theory, 22(2):327-338.

Greenaway, D., Hine, R., and Milner, C. R. (1995). "Vertical and horizontal intra-industry trade: A cross industry analysis for the United Kingdom". The Economic Journal, 105(433):1505-1518.

Hallak, J. C. (2006). "Product quality and the direction of trade". Journal of International Economics, 68(1):238-265.

Hallak, J. C. and Schott, P. K. (2011). "Estimating cross-country differences in product quality". Quarterly Journal of Economics, 126(1):417-474.

Hallak, J. C. and Sivadasan, J. (2009). "Firms' exporting behavior under quality constraints". Working Paper 14928, NBER.

Harsanyi, J. C. and Selten, R. (1988). A General Theory of Equilibrium Selection in Games. The MIT Press.

Helble, M. C. and Okubo, T. (2008). "Heterogeneous quality firms and trade costs". SSRN eLibrary.

Helpman, E. and Krugman, P. (1985). Market Structure and Foreign Trade: Increasing Returns, Imperfect Competition, and the International Economy. MIT Press, Cambridge MA.

Herguera, I., Kujal, P., and Petrakis, E. (2000). "Quantity restrictions and endogenous quality choice". International Journal of Industrial Organization, 18(8):1259-1277.

Herguera, I., Kujal, P., and Petrakis, E. (2002). "Tariffs, quality reversals and exit in vertically differentiated industries". Journal of International Economics, 58(2):467-492.

Hummels, D. and Skiba, A. (2004). "Shipping the good apples out? an empirical confirmation of the Alchian-Allen conjecture". Journal of Political Economy, 112(6):1384-1402. 
Johnson, R. C. (2010). "Trade and prices with heterogeneous firms". Mimeo, Darthmouth College.

Khandelwal, A. (2010). "The long and short (of) quality ladders". The Review of Economic Studies, 4(77):1450-1476.

Kneller, R. and Yu, Z. (2008). "Quality selection, chinese exports and theories of heterogeneous firm trade". Research Paper Series - Globalisation Productivity and Technology 2008/4, University of Nottingham.

Kugler, M. and Verhoogen, E. A. (2012). "Prices, plant size, and product quality". The Review of Economic Studies, 79(1):307-339.

Linder, S. B. (1961). An essay on trade and transformation. Almqvist \& Wiksell, Stockholm.

Manova, K. and Zhang, Z. (2012). "Export prices across firms and destinations". Quarterly Journal of Economics, 127(1):379-436.

Melitz, M. J. (2003). "The impact of trade on intra-industry reallocations and aggregate industry productivity". Econometrica, 71(6):pp. 1695-1725.

Melitz, M. J. and Ottaviano, G. I. P. (2008). "Market size, trade, and productivity". The Review of Economic Studies, 75(1):295-316.

Motta, M., Thisse, J.-F., and Cabrales, A. (1997). "On the persistence of leadership or leapfrogging in international trade". International Economic Review, 38(4):809-824.

Mussa, M. and Rosen, S. (1978). "Monopoly and product quality". Journal of Economic Theory, 18(2):301-317.

Saggi, K. and Sara, N. (2008). "National treatment and the wto: the roles of product and country heterogeneity". International Economic Review, 49(4).

Schott, P. K. (2004). "Across-product versus within-product specialization in international trade". The Quarterly Journal of Economics, 119(2):647-678.

Shaked, A. and Sutton, J. (1982). "Relaxing price competition through product differentiation". The Review of Economic Studies, 49(1):3-13.

Shaked, A. and Sutton, J. (1984). "Natural oligopolies and international trade". In H. Kierzkowski, editor, "Monopolistic competition and international trade", pages 35-50. Clarendon Press.

Sutton, J. (2007). "Quality, trade and the moving window: the globalisation process". The Economic Journal, 117(524):F469-F498.

Tirole, J. (1988). The theory of industrial organization. The MIT Press.

Verhoogen, E. A. (2008). "Trade, quality upgrading, and wage inequality in the Mexican manufacturing sector". The Quarterly Journal of Economics, 123(2):489-530. 
Wauthy, X. (1996). "Quality choice in models of vertical differentiation". The Journal of Industrial Economics, 44(3):345-353.

Wooldridge, J. (2002). Econometric analysis of cross section and panel data. The MIT Press, Cambridge MA.

Zhou, D., Spencer, B. J., and Vertinsky, I. (2002). "Strategic trade policy with endogenous choice of quality and asymmetric costs". Journal of International Economics, 56(1):205232. 